\title{
Ultrasonic Phased Array Inspection of Electrofused Joints Implemented in Polyethylene Gas Piping Systems
}

\author{
Dominique Gueugnaut ${ }^{1}$, Manuel Tessier ${ }^{2}$, Romuald Bouaffre ${ }^{1}$ and Aymeric Lopitaux ${ }^{1}$ \\ 1. ENGIE Lab-CRIGEN, Saint-Denis La Plaine F-93210, France \\ 2. Institut de Soudure Industrie, Villepinte F-93420, France
}

\begin{abstract}
PE (polyethylene) is a widespread material for the manufacturing of gas and water distribution pipelines and a large number of PE electrofusion pipe joints can be found over the thousands of kilometers of PE pipelines all over the world, thus generating an increasing interest in checking the quality of both these pipes and joints. Within the last few years it has been proved that - among the available concepts - the PAUT (phased array ultrasonic technique) was one of the most promising candidates for non destructive analysis of PE welds and pipes. No current operational NDE (non destructive examination) Technique to date has been adapted to inspect the small diameter electrofusion joints (OD from 20 to $63 \mathrm{~mm}$ ) which are frequently encountered in particular on the French gas distribution networks. In the present paper, the acuity of PAUT to detect and size both poor weld quality (e.g. cold weld) and calibrated faults has been evaluated on $63 \mathrm{~mm}$ electrofused welds by ENGIE Lab CRIGEN jointly with Institut de Soudure Industrie. Moreover the results of the PAUT evaluation and those of the destructive peel tests according to ISO 13956 standard have been confronted in order to evaluate the degree of correlation between both techniques.
\end{abstract}

Key words: PE gas pipes, electrofused joints, PAUT, peel test, calibrated faults.

\section{Introduction}

Over the last twenty years, a lot of studies have been devoted to the possible applicability on polymer materials, and especially PE (polyethylene), of the classical NDT (non-destructive techniques) designed initially for metallic materials. But given the particular structure of PE with respect to metals, the most promising ND techniques for PE reveal to be very limited in terms of both applicability and measuring capacity. Since a few years it has been demonstrated by several authors that among the available techniques the PAUT (phased array ultrasonic technique) was one of the most promising operational candidates for non destructive analysis of PE and especially PE welds realized by both butt fusion $(\mathrm{BF})$ and electrofusion (EF) [1-18]. In this context ENGIE Lab has launched

Corresponding author: Dominique Gueugnaut, materials science engineer, senior key-expert, "PE \& polymers", research fields: resins characterization, pipes and fittings processing, jointing techniques, aging, test methods, thermomechanical modelling, non destructive techniques, standardization and traceability techniques. an in-depth evaluation of the PAUT on two levels. Firstly the evaluation was focused on the PE EF joints aiming at detecting the poor welds generally referred to as "kissing bonds" or "cold welds". This work was initiated through a test program with Italian companies ISOTEST Engineering and ITALGAS focusing on the evaluation of the Korean system AIM33 which is now presented as an operational technique in Korea [19-22]. Then the work was pursued partly within the European Gas Research Group [23] and partly with the NDE Company Institut de Soudure Industrie (Villepinte, France) focusing not only on welds but also on plain pipes. Thus the capability of the PAUT was tested on both the welded assemblies and the PE pipes, with the aim of detecting and sizing the faults - artificial or natural, located both at the welded interface and in the pipe wall thickness. The range of diameters studied is mainly 20 to 200 $\mathrm{mm}$ [24-27]. As far as plain pipes are concerned, one of the major issues is to be able to detect and measure accurately the defects produced by the squeeze-off 
operation especially on the oldest gas pipes. The other important issue is to be able to detect the slow crack initiation time in the pipe wall during its overall lifetime. This issue, once validated, could give way to a possible tool for detecting the initiation time for SCG and beyond could bring input data for the validation of the 6-parameter thermo mechanical model designed by ENGIE Lab aiming at describing the SCG (Slow Crack Growth) process in different loading conditions including over stresses [28-32]. Regarding specifically the electrofused assemblies, even if the PAUT procedures have been gradually and more systematically improved for detecting poor welds, some questions remain to be addressed regarding the degree of correlation between PAUT and the ISO 13956 standard requirements of the destructive peel tests on the one hand, and regarding the influence of the flaws detected on the long term performance of the welds on the other hand [31, 33-35].

The experimental program presented in this paper comprises testing of 84 electrofused assemblies (63 $\mathrm{mm}$ pipe-saddle) with calibrated non-weldable zones applied deliberately at the pipe-saddle interface prior to welding both at the nominal heating time (56 assemblies) and at $80 \%$ of the nominal time (28 assemblies).

\section{Experimental Setup}

\subsection{Preparation of Electrofused Assemblies with Calibrated Flaws}

Two experimental campaigns were designed to assess for acuity of the PAUT for detecting faults at the interface of $63 \mathrm{~mm}$-electrofused assemblies [25]. The first one included a set of 56 assemblies welded with the nominal heating time and the second one included a set of 28 assemblies welded with a reduced (0.8) heating time. For both sets of samples, deliberate faults were created in the weld plane by integrating discrete non-weldable zones at the interface pipe-saddle, comprising adhesive coated paper strips $-0.08 \mathrm{~mm}$ thick, placed regularly at the theoretical weld zone of the saddles in order to design three different configurations, as illustrated in Fig. 1. Both pipe and saddles were made of an ethylene-butene copolymer PE 100 grade currently used and complying with the NF EN 1555 standard for gas distribution piping systems [35]. The pipe was a standard gas pipe with a nominal diameter of $63 \mathrm{~mm}$ and a nominal thickness of $5.8 \mathrm{~mm}$.

The density and the location of the strips were calculated so that they fall on either side of the criteria recommended with respect to standard ISO 13956 [33], as illustrated in Table 1.

The 56 welds at the nominal heating time were processed automatically at room temperature, by reading bar codes using an electrofusion welding machine. The 28 welds at $80 \%$ of the nominal heating time were processed manually at room temperature programming the reduced heating time on the welding machine. All the welds were carried out leaving a minimum space of around $20 \mathrm{~mm}$ between each saddle in order to avoid any disturbing heat transfers between neighbors, as illustrated in Fig. 2.

In order to improve access for the ultrasonic probe during the inspection of the assembly, half of the saddles were subjected to surface grinding using a mechanical tool. This operation, while rather coarse, made it possible to locally eliminate bumps or thicknesses on the accessory, as illustrated in Fig. 3.

\subsection{PAUT Evaluation of the Welded Assemblies}

$\mathrm{PE}$ is a particular material with some specific acoustic characteristics which can turn it into a difficult material to inspect using ultrasonic waves. It has been already demonstrated throughout the literature that PE is a highly attenuative material. This means that special care shall be taken when selecting the frequency of the ultrasonic phased array transducer and also that only LWs (longitudinal waves) are to be used for the evaluation of the integrity of $\mathrm{PE}$ components; SWs (shear waves) cannot be used in PE 

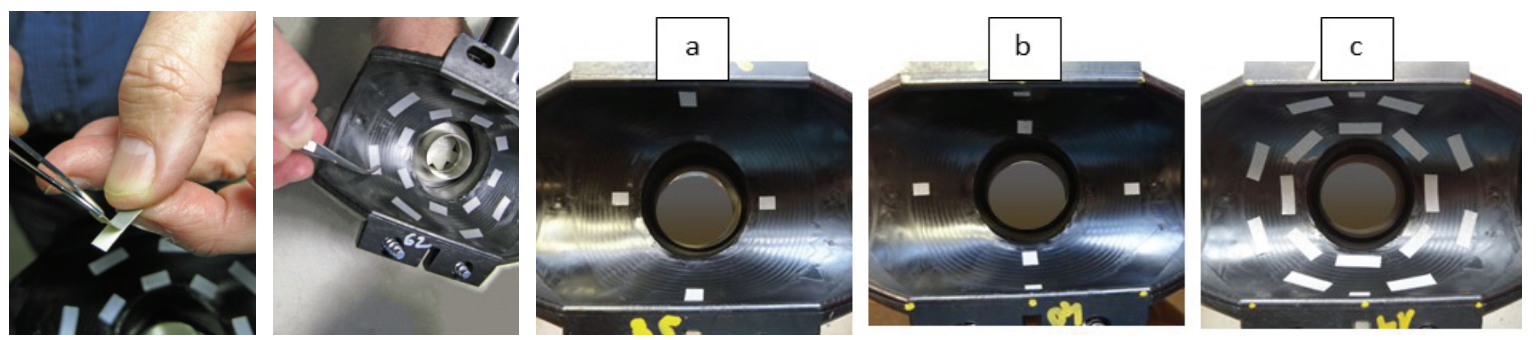

Fig. 1 Application of adhesive strips on the theoretical weld zone for the saddle ("cross" configuration T1 (a); "cross" configuration T2 (b); “mass" configuration (c).

Table 1 Proportions of non-weldable zones ("cross" and "mass" configurations) applied to the surface of the $63 \mathbf{m m} \times 20$ mm saddles via adhesive strips. Requirements in ISO 13956 (Annex A): $L_{d}=$ Percentage of decohesion in cross configuration $=1 / y \leq 50 \%$ and $A d=$ Percentage of "total surface" decohesion $=A / A_{n o m} \leq 25 \%$. $\left(A_{n o m}=\right.$ Total theoretical surface area of the welded zone).

\begin{tabular}{lccccc}
\hline Configuration & \multicolumn{5}{c}{$\mathrm{L} / \mathrm{Y}_{\text {nom }}$} \\
$\mathrm{A} / \mathrm{A}_{\text {nom }}$
\end{tabular}
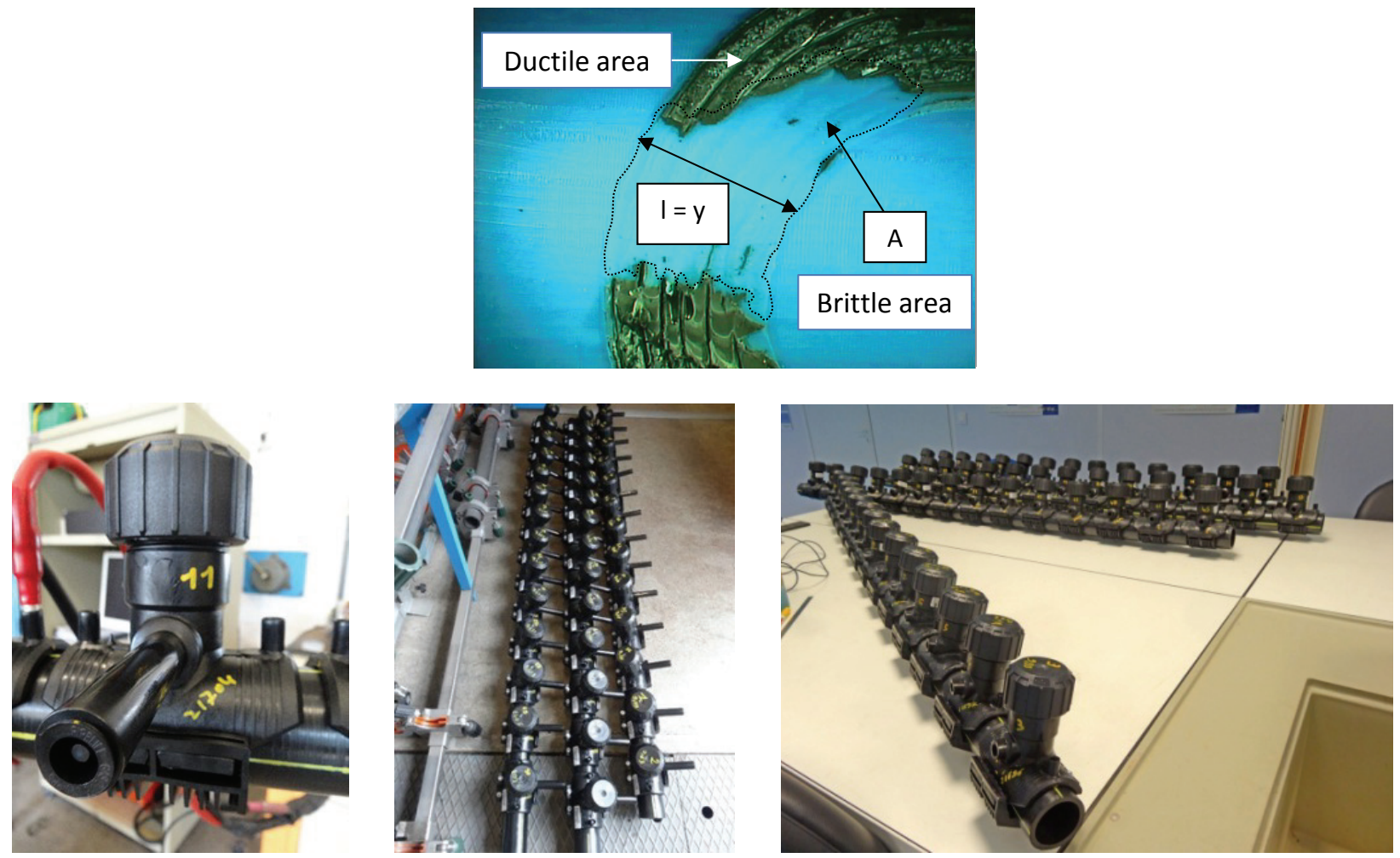

Fig. 2 Welding of the pipe-saddle assemblies. 

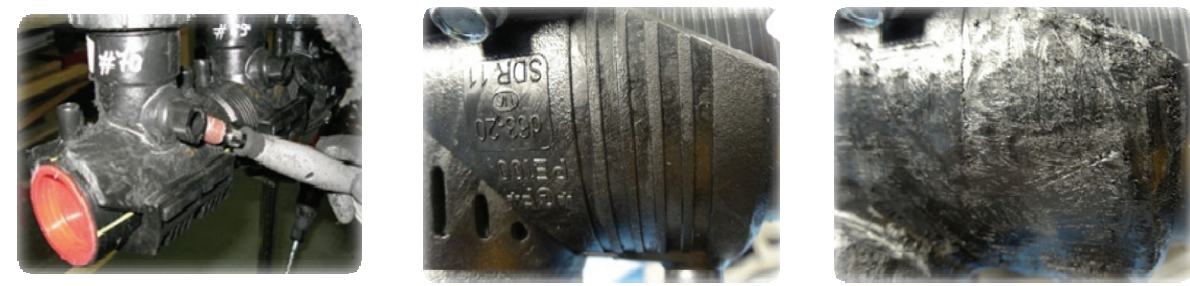

Fig. 3 Mechanical grinding and resulting state of the external surface of the saddle.

since they are attenuated much more rapidly than LW. The velocity of LW has been evaluated on various calibration blocks from different PE grades; the value commonly used is around $2,200 \mathrm{~m} / \mathrm{s}$. The sensitivity of the examination, depending on the application, has been set using appropriate reference blocks containing adequate reflectors such as SDHs (side-drilled holes), FBHs (flat-bottom holes) or notches. The nature, location and dimensions of those reference reflectors are usually determined by the performance of the examination looked for. The phased array ultrasonic technique used for the examination of different types of PE components suffers from the same hurdles as those encountered with conventional ultrasonic techniques but those can be easily overcome by the flexibility of PAUT [36]. Indeed, essential inspection parameters like component geometry (pipe-sleeve, pipe-saddle, spigot-fitting or pipe), surface condition or inspection target area may require the use of phased array transducers with small or large footprints, specific wedges with curvature adapted to pipes or specific phased array settings (beam steering and/or focusing, filtering, display).

The inspection of the pipe-saddle assemblies was performed via an Olympus 10L16-A00 16-element PA probe with a frequency of $10 \mathrm{MHz}$ in direct contact with the test piece. The PA probe was linked to an Olympus OmniScan 16128. Multiple beams using LW of incidence angles varying by steps of $1^{\circ}$ within a range of $-30^{\circ}$ to $+30^{\circ}$ have been generated and displayed in an S-Scan sector image. A thixotropic gel ensured the coupling between the surface of the probe and the test piece. The small size of the sensor (around $5 \mathrm{~mm} \times 5 \mathrm{~mm}$ of active surface) made it possible to inspect nearly the entire welded zone without contact problems.

The electrofusion fitting was inspected by sweeping the part as evenly as possible. Regularity was better for a sleeve fitting than for a saddle, due to the more complex geometry of the latter, linked to the presence of connectors, outlet, fusion indicators, and stamps, as illustrated in Fig. 4.

In order to access a level of quantitative analysis of PAUT results, the so-called POD (probability of detection) of fault was used [23-26] according to its definition: probability of detection of an existing fault by NDE divided by the total number of welds with existing faults. In this formulation, the quantity of the denominator is the sum of the faults detected by NDE (quantity in the numerator) and those that exist but are not detected by NDE. Accordingly, the higher the POD, the greater the probability of detection of faults using the NDE technique employed.

\subsection{Destructive Testing of the Assemblies}

Destructive testing of assemblies was performed as per ISO 13956 standard according to configuration A2 (peel) at ambient temperature, with a tensile rate of 20 $\mathrm{mm} / \mathrm{min}[19,25]$, as illustrated in Fig. 5.

\subsection{Sizing of the Non-welded Areas on the Peeled Assemblies}

In order to quantify the non-welded zones after the destructive tests, a mapping of the peeled surfaces has been done by means of a specific mechanical device installed on a LEICA $\mathrm{MZ}_{12.5}$ microscope associated with an image processing system, as illustrated in Fig. 6. 


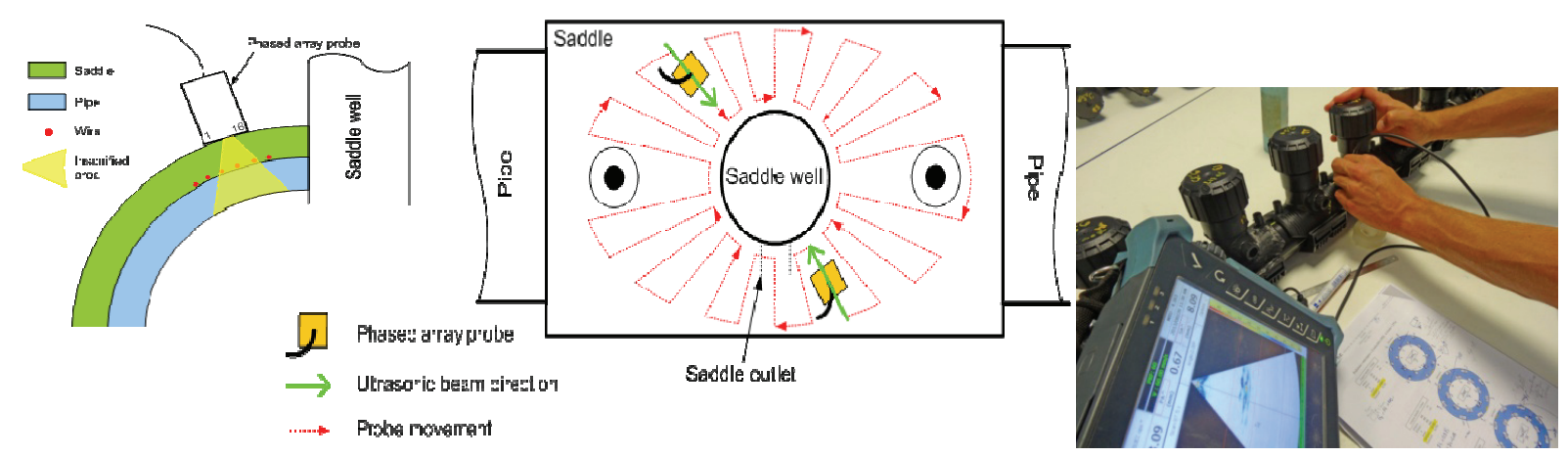

Fig. 4 PAUT inspection of a saddle that can be electrofusion-welded.
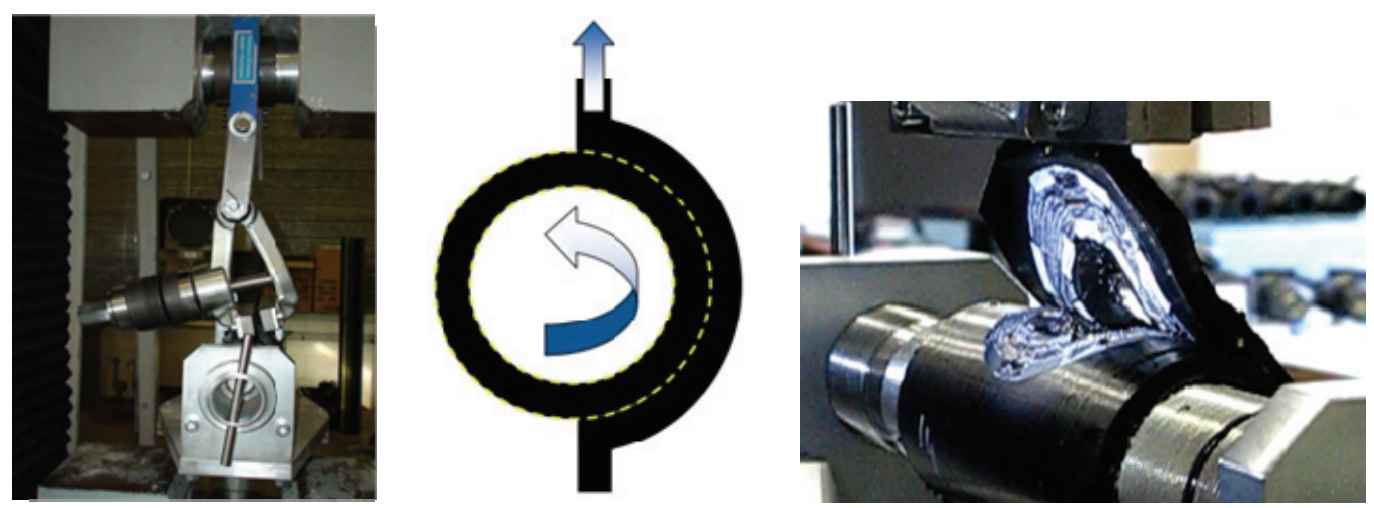

Fig. 5 Destructive peeling of an EF saddle revealing the calibrated non-welded zones.
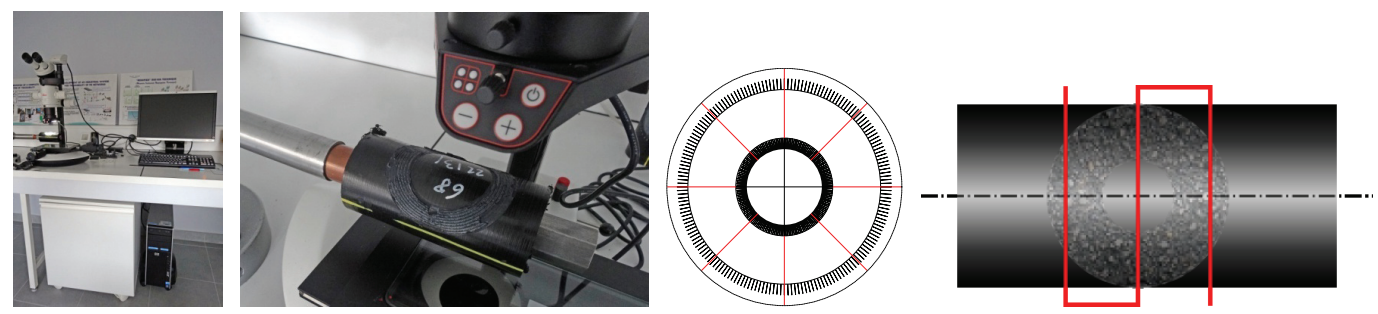

Fig. 6 Optical microscopy bench for mapping of the peeled surfaces of the welded assemblies. The complete scanning of the surface is made by rotating and translating the specimen. A "flattening" of the scanned surface is computed afterwards and the computed analysis of the different areas is done by means of dedicated image analysis software with the help of a specific scaled gauge.

\section{Results and Discussion}

\subsection{Detection and Sizing of the Faults in the} Assemblies Welded with the Nominal Heating Time

Within the framework of a first test campaign, 256 strips and 160 strips were researched respectively for the "mass" configuration and for the "cross" configuration. Fig. 7 gives by way of example the S-Scan of the detection of one of the strips placed in the periphery of the heating area of saddle referred to as $\# 11\left(\mathrm{~A} / \mathrm{A}_{\text {nom }}=22.7 \%\right)$.
The strip is perfectly detected (intersection of red lines) at depth corresponding to the position of the pipe-saddle interface (distance between the top and the horizontal red line) and at a $1 \mathrm{~mm}$ distance from the wires (distance between blue and red horizontal lines). The 256 strips in "mass configuration" are detected by PAUT, hence a POD of $100 \%$. However, for a gain increased by $+6 \mathrm{~dB}$ (normal conditions +6 $\mathrm{dB}$ ), the surface condition of the saddles influences the PAUT response, specifically the presence of striations or the presence of the fusion indicator or the 
existence of local instances of excess thickness. In this case, the grinded saddle presents a better foundation for the analysis of the welded assembly, as illustrated by way of example in Fig. 8 .

The grinding of the saddle then leads to detection rates that always exceed those obtained from an as-received one. In addition, the transition to a gain augmented by $+12 \mathrm{~dB}$ for around 60 strips (i.e. around one quarter of the total number of strips implemented) makes it possible to refine detection.

A preliminary attempt to measure the dimensions of the strips detected was performed in four cases, as indicated in Table 2.

The analysis of these results shows that while the width of the strip is hard to measure in 5 out of 7 cases, the estimate for the two remaining cases is relatively correct. With regard to the detected length, the PAUT measure is overestimated in the 7 cases.
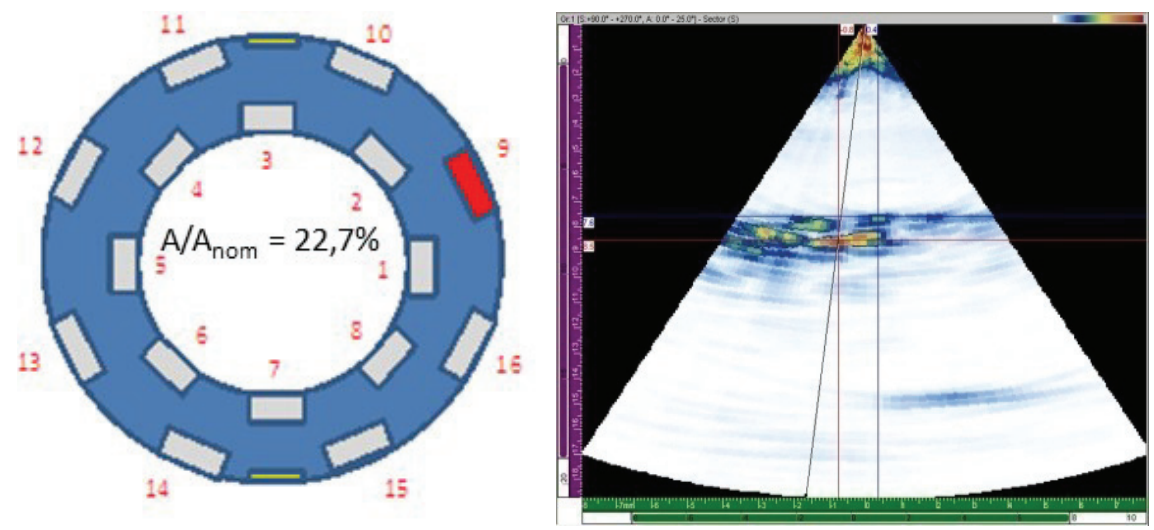

Fig. 7 PAUT detection of strip 9 applied in the periphery of the heating zone of saddle \#11 (A/A $\mathbf{A}_{\text {nom }}=\mathbf{2 2 . 7 \%}$ "mass").
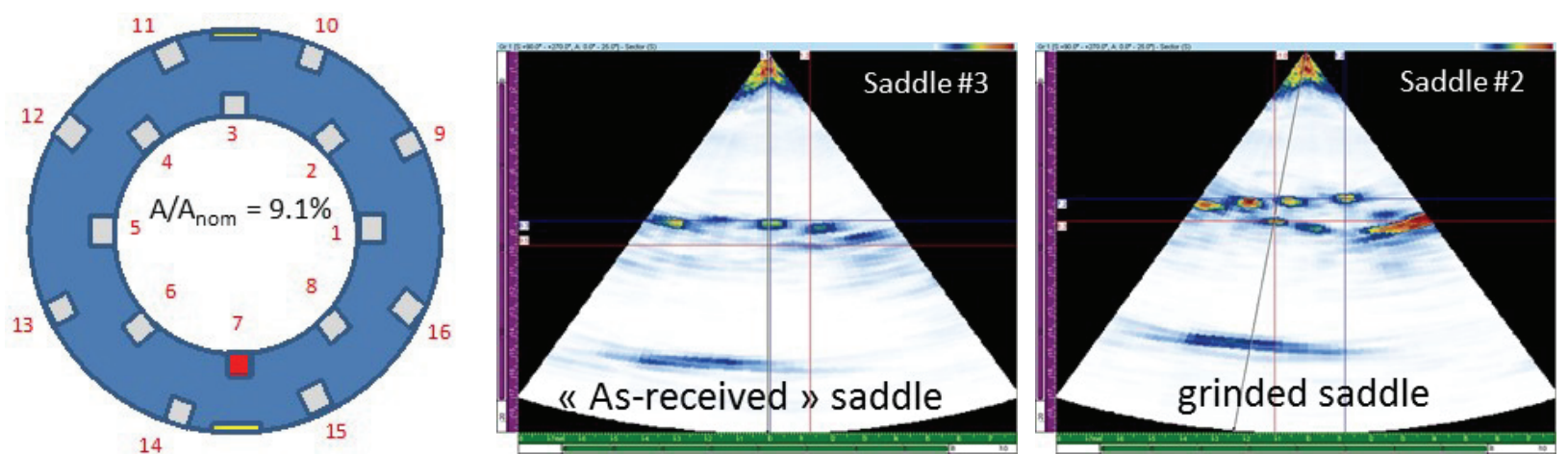

Fig. 8 PAUT detection of strip 7 on the rough saddle $\# 3\left(\mathrm{~A} / \mathrm{A}_{\mathrm{nom}}=9.1 \%\right)($ middle $)$ and on the grinded saddle $\# 2\left(\mathrm{~A} / \mathrm{A}_{\mathrm{nom}}=\right.$ 9.1\%) (right).

Table 2 Estimate of the dimensions detected at the pipe-saddle interface for the "mass" configuration ((*) width hard to measure).

\begin{tabular}{llll}
\hline Saddle No. & Position of the strip & $\begin{array}{l}\text { Theoretical dimensions of } \\
\text { the implemented strip } \\
\text { (width } \times \text { length) }\end{array}$ & $\begin{array}{l}\text { Dimensions of the strip } \\
\text { evaluated by PAUT } \\
\text { (width } \times \text { length) }\end{array}$ \\
\hline 3 & 3 & $4.5 \mathrm{~mm} \times 5 \mathrm{~mm}$ & $\sim 7 \mathrm{~mm} \times 10 \mathrm{~mm}$ \\
7 & 15 & $4.5 \mathrm{~mm} \times 5 \mathrm{~mm}$ & $\sim 5 \mathrm{~mm} \times 9 \mathrm{~mm}$ \\
11 & 3 & $4.5 \mathrm{~mm} \times 10 \mathrm{~mm}$ & $\sim \ldots \times 12 \mathrm{~mm}\left(^{*}\right)$ \\
& 8 & $4.5 \mathrm{~mm} \times 10 \mathrm{~mm}$ & $\sim \ldots \times 12 \mathrm{~mm}\left(^{*}\right)$ \\
15 & 9 & $4.5 \mathrm{~mm} \times 15 \mathrm{~mm}$ & $\sim \ldots \times 16 \mathrm{~mm}\left(^{*}\right)$ \\
& 3 & $4.5 \mathrm{~mm} \times 15 \mathrm{~mm}$ & $\sim \ldots \times 16 \mathrm{~mm}\left(^{*}\right)$ \\
& 15 & $4.5 \mathrm{~mm} \times 15 \mathrm{~mm}$ & $\sim \ldots \times 17 \mathrm{~mm}\left(^{*}\right)$ \\
\hline
\end{tabular}


For theoretical lengths less than $5 \mathrm{~mm}$, the overestimate is very significant. On the other hand, it is quite accurate for strips bigger than $5 \mathrm{~mm}$. The biggest overestimate observed in the case of small strips could be due to the dimensions of the focal spot of the ultrasonic beam, which are around $6 \mathrm{~mm} \times 6$ $\mathrm{mm}$ and therefore bigger than the faults encountered.

For applied "cross" faults, of the 160 strips implemented in T1 and T2 cross configurations, 129 are detected immediately, resulting in a total POD of around $81 \%$. This can be obtained by doubling or quadrupling the original gain. The remaining 31 strips are not detected due to difficulties in the probe accessing areas of interest, especially when the strip dimensions are smaller.

Fig. 9 shows the S-Scans for a strip placed in the interior periphery (T1) of the heating zone of saddles referred to as \#28 $(1 / \mathrm{y}=13.6 \%)$ and $\# 43(1 / y=50 \%)$. The S-Scans show the excellent level of detection of two strips having very different dimensions $(3 \mathrm{~mm}$ and $11 \mathrm{~mm}$-long, respectively) located at relatively inaccessible positions (near the saddle well). Detection is easier since the impact of the ultrasonic beam is maximal (Saddle \#43, strip 4). If the cross configurations (T1 and T2) are below 27.3\%, the POD remains very low. On the other hand, once this experimental value is reached, the POD is close to $100 \%$, enabling correct detection at the ISO standard requirement threshold transition (50\% "cross").

As for the "mass" configuration, an attempt to measure the dimensions of the strips detected was performed in some cases for the "cross" configuration, as indicated in Table 3. The analysis of the 4 cases studied shows that the PAUT estimate leads to values that are quite close to reality in terms of the length of the strip ("cross"), but with a systematically overestimated width of around $33 \%$ to $100 \%$.

\subsection{Detection and Sizing of the Faults in the Assemblies Welded with an 80\%-Heating Time}

The 28-assemblies test campaign was carried out in order to evaluate the capacity of PAUT to detect and
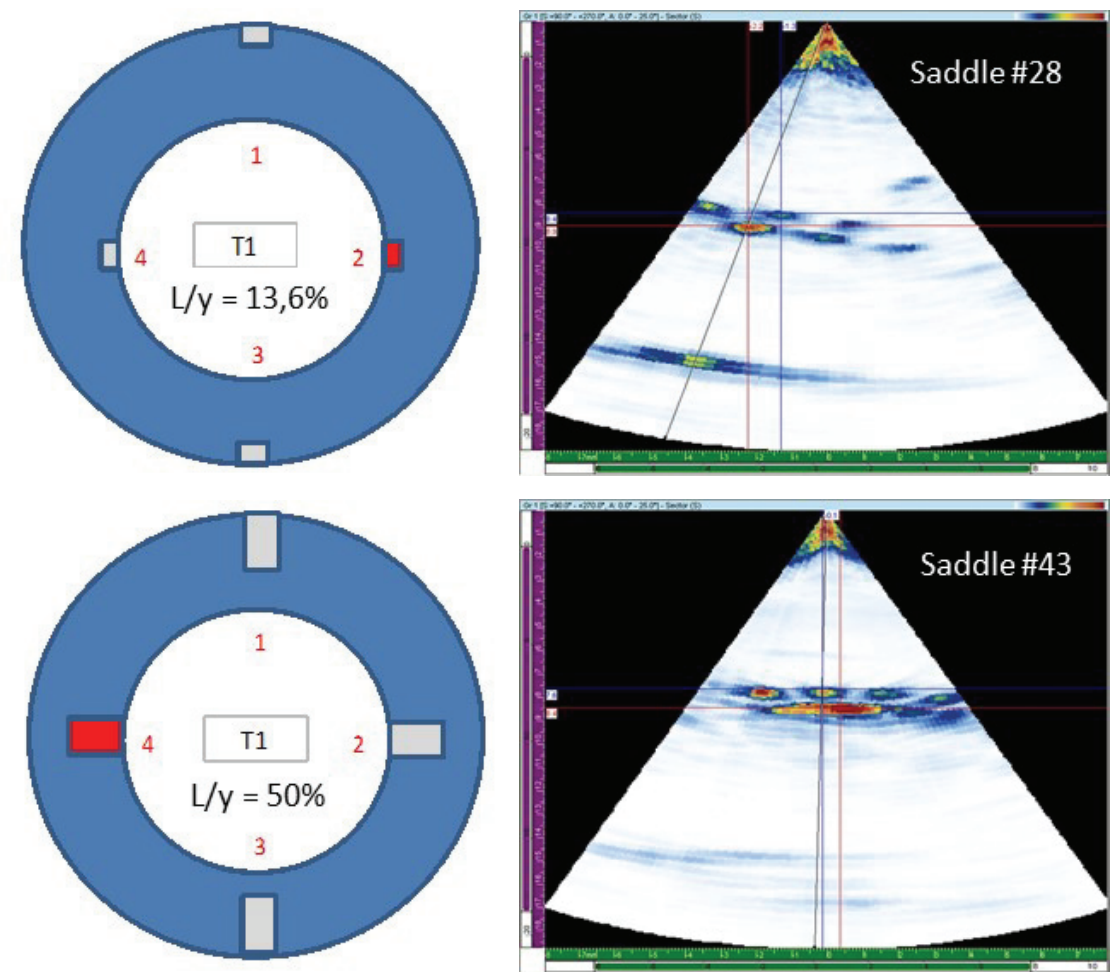

Fig. 9 PAUT detection of strips 2 (top) and 4 (bottom) applied in the interior periphery of the heating zone of Saddles \#28 $(\mathrm{l} / \mathrm{y}=\mathbf{1 3 . 6} \%)$ and $\# 43(\mathrm{l} / \mathrm{y}=\mathbf{5 0 \%})$ ("cross" configuration T1). 
Table 3 Estimate of the dimensions of the strips detected at the pipe-saddle interface for the "cross" configurations (T1 and T2).

\begin{tabular}{llll}
\hline Saddle No. & Position of the strip & $\begin{array}{l}\text { Theoretical dimensions of the } \\
\text { implemented strip } \\
\text { (width } \times \text { length) }\end{array}$ & $\begin{array}{l}\text { dimensions of the strip } \\
\text { evaluated by PAUT } \\
\text { (width } \times \text { length) }\end{array}$ \\
\hline 39 & 1 & $4.5 \mathrm{~mm} \times 6 \mathrm{~mm}$ & $\sim 6 \mathrm{~mm} \times 9 \mathrm{~mm}$ \\
$\begin{array}{l}\text { Cross T2) } \\
\begin{array}{l}\text { Cross T1) } \\
47\end{array}\end{array}$ & 4 & $4.5 \mathrm{~mm} \times 11 \mathrm{~mm}$ & $\sim 7 \mathrm{~mm} \times 10 \mathrm{~mm}$ \\
$($ Cross T2) & 1 & $4.5 \mathrm{~mm} \times 11 \mathrm{~mm}$ & $\sim 7 \mathrm{~mm} \times 12 \mathrm{~mm}$ \\
$\begin{array}{l}55 \\
(\text { Cross T2) }\end{array}$ & 1 & $4.5 \mathrm{~mm} \times 14 \mathrm{~mm}$ & $\sim 9 \mathrm{~mm} \times 12 \mathrm{~mm}$ \\
\hline
\end{tabular}

measure both the calibrated faults and the zones improperly welded as a consequence of the reduced heating time. In these welded assemblies, 128 strips and 80 strips were researched respectively for the "mass" configuration and for the "cross" configurations (T1 and T2). Fig. 10 gives an example of the S-Scans obtained on saddles with calibrated faults in "mass" configuration.

For "mass" faults, the 128 strips are detected, even for the lowest proportion (9.1\%), hence a POD of $100 \%$. Moreover, PAUT reveals additional anomalies with some saddles located mainly on the external "ring" materialized by the outermost strips. From the data obtained on 8 assemblies, an attempt for sizing the overall faults is presented in Table 4. PAUT sizing is possible for 126 strips on 128 (98.5\%). The estimated widths, between $4 \mathrm{~mm}$ and $6 \mathrm{~mm}$, are very close to the real ones, even if these dimensions are also very close to the focal spot of the UT beam. The estimated lengths are greater than the real ones. Considering a $30 \%$ error on the measurement (as for the widths), it is possible to reveal about 50 cases for which additional disorders, other than those of the non-weldable striped areas, do exist (some of them circled in Table 4, as a way of an example).

Several other anomalies which are not detected but lowering the error from $30 \%$ to $20 \%$ allows one to increase the over sizing level to 98 cases on 126. Consequently the zones improperly welded, excluding the ones of the calibrated defects, measured by PAUT stand between $14 \%$ and $53 \%$ of the overall surface improperly welded.
For "cross" faults, 67 strips on the 80 are detected, even for the lowest proportion $(9.1 \%)$. The averaged POD values are of the order of $82.5 \%$ and $72.5 \%$ for the $\mathrm{T} 1$ and $\mathrm{T} 2$ configurations respectively, and grinding the saddles does not improve the detection. Nevertheless, for the configuration $\mathrm{T} 1$, the individual POD is $100 \%$ for $\mathrm{L} / \mathrm{y}$ higher than $13.7 \%$. PAUT sizing is possible for only 37 strips for which the estimated widths are slightly higher than the real ones. Considering a $30 \%$ error on the measurement of the lengths (as for the widths), it is possible to reveal about 21 cases (11 on 16 and 10 on 16 for the configuration $\mathrm{L} / \mathrm{y}=9.1 \%$ and $\mathrm{L} / \mathrm{y}=13.7 \%$ respectively) for which additional disorders, other than those of the non-weldable striped areas, do exist.

\subsection{Destructive Peel Tests on the Welded Assemblies}

In order to initiate peeling in due form, it was necessary in certain cases to do a cutter incision with consequently a deterioration and an occultation of certain strips placed at the edge, mainly in "cross" mode where the small size of certain strips further amplifies this masking phenomenon. However, it was possible to perform the test correctly in the majority of cases, clearly revealing the number and the position of the strips, as illustrated in Table 5.

It can be observed that for "mass" faults, the revelatory power of the peel test is nearly $100 \%$. It is not $100 \%$ due to the concealment of a few strips resulting from the cutter incision. On the other hand, the strips in "cross" configuration are revealed only at $71 \%$ to $72.5 \%$, with configuration $\mathrm{T} 2$ being increasingly 


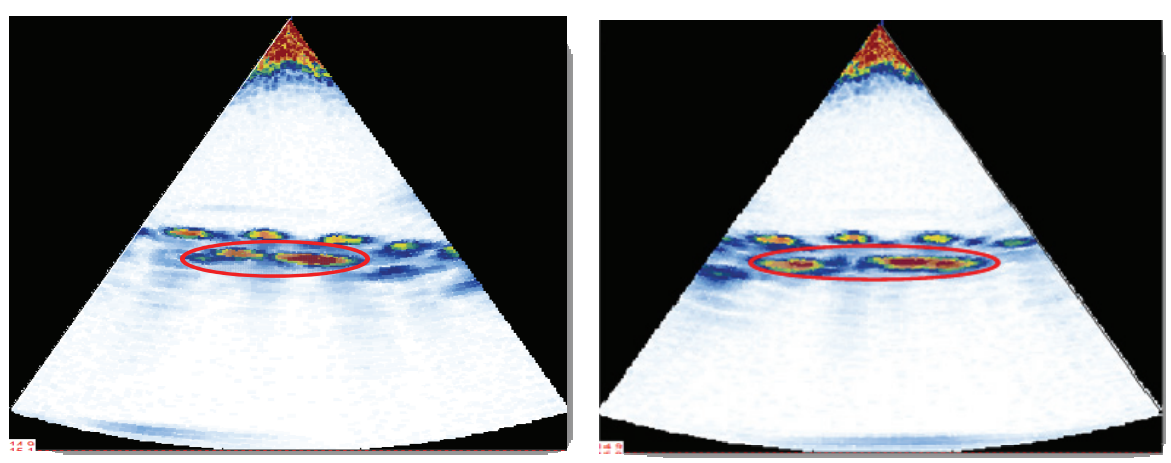

Fig. 10 S-Scans of two Saddles (\#60 \& \#63) revealing the calibrated defects and additional anomalies.

Table 4 Sizing of the faults $(\mathrm{mm} \times \mathbf{m m})$ detected by PAUT in the welds (*grinded saddle).

\begin{tabular}{|c|c|c|c|c|c|c|c|c|c|c|c|c|c|c|c|c|}
\hline & & \multicolumn{15}{|c|}{ No. and position of the adhesive strip } \\
\hline & & \multicolumn{8}{|c|}{ External "ring" } & \multicolumn{7}{|c|}{ Internal "ring" } \\
\hline & & 1 & 2 & 3 & 4 & 5 & 6 & 7 & 8 & 9 & 10 & 11 & 12 & 13 & 14 & 16 \\
\hline 57 & Mass & $6 \times 6$ & $5 \times 6$ & $5 \times 7$ & $5 \times 9$ & -- & $5 \times 7$ & $5 \times 9$ & $6 \times 6$ & $4 \times 9$ & $4 \times 7$ & $5 \times 8$ & $6 \times 8$ & -- & $6 \times 8$ & $4 \times 9$ \\
\hline $58 *$ & $9.1 \%$ & $6 \times 6$ & $5 \times 8$ & $5 \times 8$ & $5 \times 6$ & $5 \times 6$ & $5 \times 12$ & $5 \times 10$ & $6 \times 6$ & $5 \times 6$ & $5 \times 9$ & $5 \times 8$ & $5 \times 6$ & $6 \times 6$ & $5 \times 6$ & $6 \times 6$ \\
\hline 59 & Mass & $5 \times 9$ & $5 \times 15$ & $5 \times 16$ & $5 \times 6$ & $5 \times 7$ & $5 \times 16$ & $5 \times 16$ & $5 \times 16$ & $5 \times 15$ & $5 \times 12$ & $4 \times 12$ & $5 \times 12$ & $5 \times 13$ & $4 \times 12 \quad 5 \times 12$ & $5 \times 14$ \\
\hline $60 *$ & $18.2 \%$ & $5 \times 7<$ & $5 \times 14$ & $5 \times 14$ & $5 \times 16$ & $5 \times 16$ & $5 \times 12$ & $5 \times 15$ & $5 \times 15$ & $5 \times 12$ & $5 \times 13$ & $5 \times 12$ & $5 \times 38$ & $5 \times 38$ & $5 \times 38>5 \times 13$ & $5 \times 13$ \\
\hline 61 & Mass & $5 \times 17$ & $5 \times 18$ & $5 \times 17$ & $5 \times 18$ & $5 \times 18$ & $5 \times 17$ & $5 \times 18$ & $5 \times 17$ & $5 \times 12$ & $5 \times 12$ & $5 \times 12$ & $5 \times 12$ & $5 \times 12$ & $5 \times 12 \quad 5 \times 13$ & $5 \times 11$ \\
\hline $62 *$ & $22.7 \%$ & $5 \times 17$ & $5 \times 16$ & $5 \times 18$ & $5 \times 18$ & $5 \times 18$ & $5 \times 20$ & $5 \times 16$ & $5 \times 17$ & $5 \times 10$ & $5 \times 11$ & $5 \times 12$ & $5 \times 12$ & $5 \times 10$ & $5 \times 11 \quad 5 \times 11$ & $5 \times 10$ \\
\hline$\overline{63}$ & Mass & $5 \times 16$ & $5 \times 18$ & $5 \times 18$ & $5 \times 18$ & $5 \times 17$ & $5 \times 18$ & $5 \times 18$ & $5 \times 16$ & $5 \times 36$ & $5 \times 36$ & $5 \times 18$ & $5 \times 19$ & $5 \times 14$ & $5 \times 19 \quad 5 \times 18$ & $5 \times 36$ \\
\hline $64 *$ & $27.3 \%$ & $5 \times 16$ & $5 \times 19$ & $5 \times 18$ & $5 \times 18$ & $5 \times 18$ & $5 \times 18$ & $5 \times 21$ & $5 \times 16$ & $5 \times 17$ & $5 \times 18$ & $5 \times 17$ & $5 \times 52$ & $5 \times 52$ & $5 \times 52>5 \times 17$ & $5 \times 19$ \\
\hline
\end{tabular}

Table 5 Total revelatory power of the destructive peel test for "mass" and "cross" fault configurations.

\begin{tabular}{lll}
\hline Configuration & Total number of strips detected & Revelatory power of the peel test \\
\hline Mass & $254 / 256$ & $99.2 \%$ \\
$9.1 \%, 18.2 \%, 22.7 \%, 27.3 \%$ & $58 / 80$ & $72.5 \%$ \\
Cross T1 & $57 / 80$ & $71 \%$ \\
$\begin{array}{l}\text { Cross T2 } 13.6 \%, 27.3 \%, 50 \%, 63.6 \% \\
9.1 \%, 13.6 \%, 27.3 \%, 50 \%, 63.6 \%\end{array}$ & $51 \%$ \\
\hline
\end{tabular}

difficult to process, specifically for the lowest "cross" percentages, and bearing in mind the very small size of the strips and the cutter incision needed to initiate the cracking.

The peel energy was calculated on the basis of the "Force-Displacement" curves recorded by the tensile machine during the peel test as illustrated in Fig. 11.

The integration of the curves with respect to the tensile machine displacement is initially similar to the energy needed for peeling the assembly (ignoring creep in the material held in the upper jaw and comparing the rotational displacement on the welded surface to the vertical displacement).

Bearing in mind the experimental difficulties linked to the performance of the test (cutter incision, creep or bending of the saddle during the test that often requires performing the test in multiple sequences by reversing the saddle) and despite the experimental dispersions, it can be noted that the average peel energies are higher for assemblies with "cross" faults than those obtained for assemblies with "mass" faults. This was expected, bearing in mind the higher "mass equivalent" percentage for this latter configuration.

The results of the PAUT technique can be compared with the results from the destructive peel test in order to evaluate the degree of correlation that might exist between these two totally independent methods.

First, for the configuration of "mass" faults, the revelatory power of the destructive test is less than but 


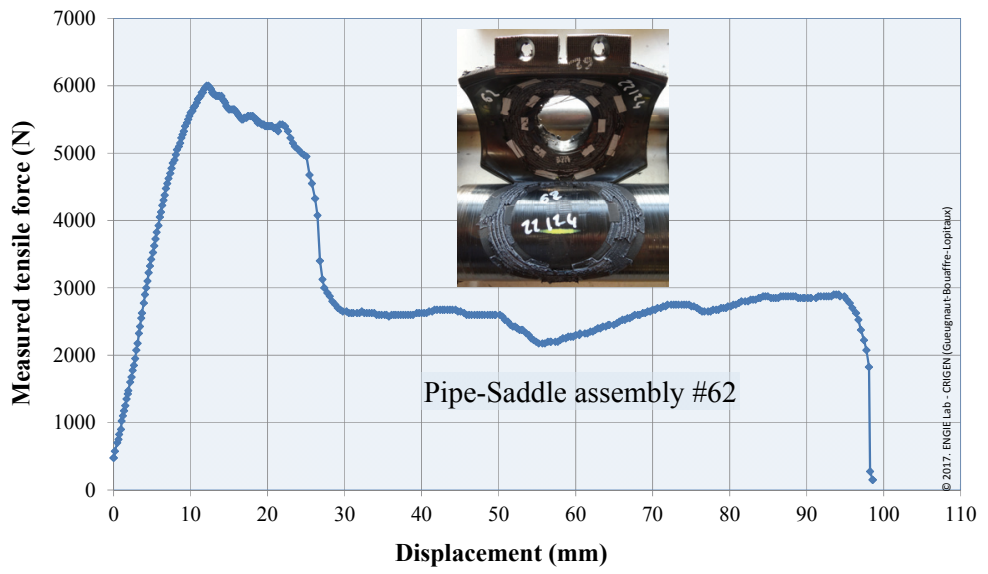

Fig. 11 Revelation of the position of the strips after the destructive peel test (Saddle \#62).

close to the probability of detection of PAUT. However, it should be noted that the destructive test revealed, in two cases of the 16 processed, "cross" non-welded zones not detected ahead of time by PAUT. The presence of these non-welded zones is not explained at this stage of the study. Second, for the T1 cross configuration, the revelatory power of the destructive test is still less than the POD of PAUT, except for the highest percentages in the inspected non-welded zones (assemblies \#49 to \#56), where non-destructive and destructive testing align. Then, for the $\mathrm{T} 2$ cross configuration, the revelatory power of the destructive test is comparable to the POD of PAUT, or even to a higher level in some cases (e.g. assemblies \#23, \#24, \#47 or \#48).

\subsection{Computed Sizing of the Faults on the Peeled Specimens}

The results of the PAUT inspection were then compared with those obtained after computation of the peeled surfaces. Fig. 12 displays, as a way of an example, the localization of the different revealed areas corresponding to both the welded zones and the non-welded zones including the non-weldable zones of the strips, for the "mass" configuration and the "cross" configuration.

The analysis of all the results reveals that some of the additional disorders cannot be detected or sized by PAUT scanning. Nevertheless, it is possible to size in a fairly good way a significant number of additional disorders corresponding to the non-welded areas due to the insufficient heating time on the 28 assemblies. As a way of an example, Fig. 13 displays the overall surfaces of the defects (calibrated strips in "mass" configuration + non-welded areas) calculated from the PAUT sizing for 8 welds with regard to the total surface occupied by the strips. The gap between both measurements gives a clear indication of the additional non-welded zones due to the insufficient heating time.

In order to evaluate the accuracy of the evaluation of the non-welded zones with regard to the ISO 13956 requirements, visual inspection was confronted to compute imaging of the peeled specimens, as illustrated in Fig. 14.

The comparison of these data shows that the visual inspection underestimates the $25 \%$ threshold of the ISO standard since the image analysis gives values between $30 \%$ and $45 \%$. In this case, the visual inspection would accept a weld which must be rejected on the basis of image analysis.

Moreover, a visual inspection of $20 \%$ would lead to accepting the weld according to the ISO Standard requirement although rejected on the basis of the image analysis with values between $27 \%$ and $38 \%$ and consequently greater than $25 \%$.

In the same way, the $50 \%$ threshold in "cross" configuration as evaluated by visual inspection can be 

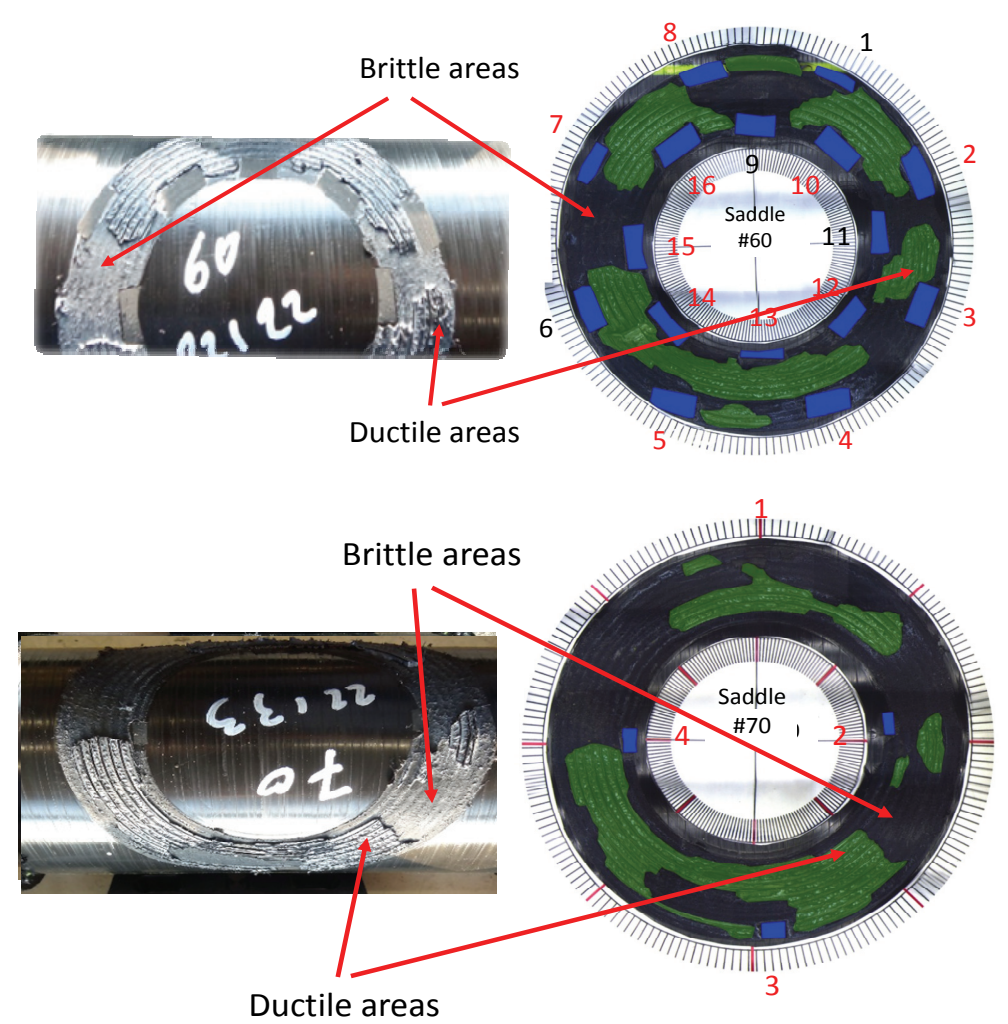

Fig. 12 Localization of the anomalies on the peeled specimens for the "mass" configuration (top) and the "cross" configuration (bottom). Strips come in blue color. The so-called "ductile" zones (good weld) appear in green color. The black zones correspond to the additional non-welded zones. The numbers in red color correspond to the strips where additional disorders were detected and sized by PAUT.

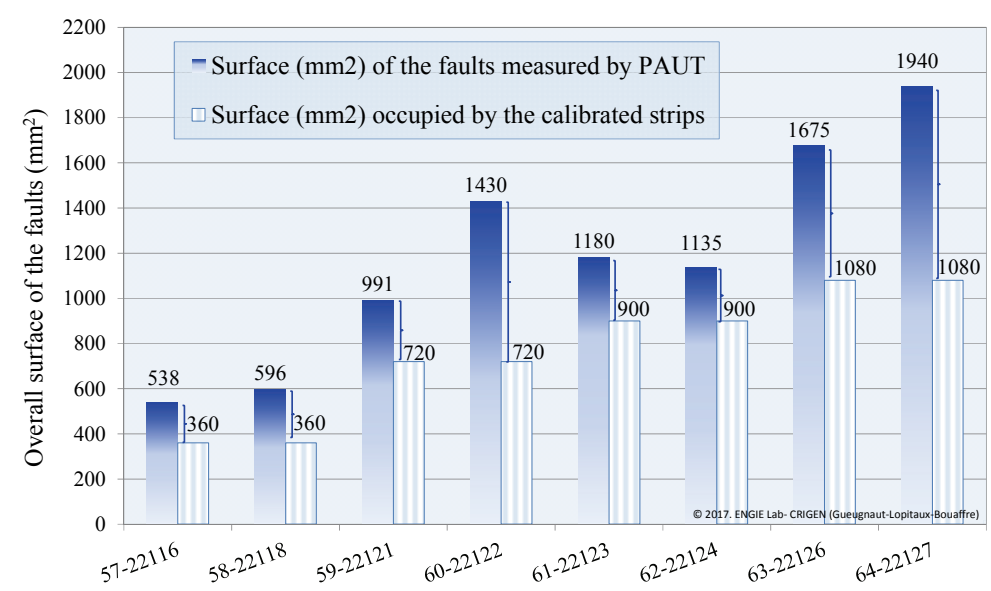

Fig. 13 Improperly welded zones in the saddles with calibrated defects in "mass" configuration. 


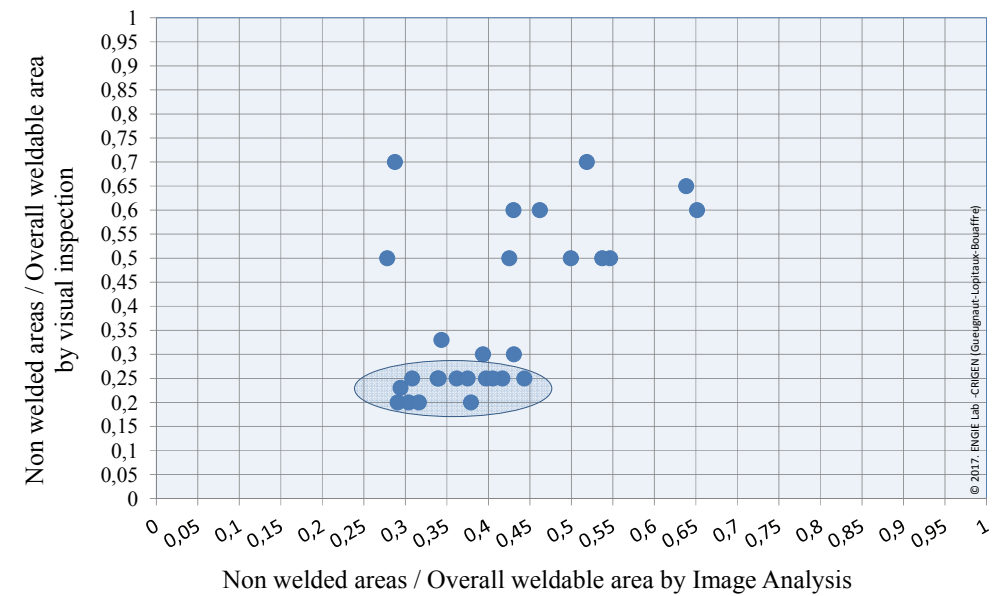

Fig. 14 Comparison of the quantitative analysis of the non-welded areas resulting from either visual inspection or image analysis.

erroneous, compared to the more accurate image analysis which gives individual values in the range of 28\%-55\%.

\section{Conclusions}

The non-destructive PAUT testing of a series of 84 electrofused assemblies with non-weldable zones deliberately applied to the pipe-saddle interface prior to welding shows the very good acuity of this technique in terms of both probability of detection and sizing of the faults either calibrated (paper strips) or induced by the reduced heating time. The so-called "mass" faults are easier to detect and to size than the "cross" ones due to the presence of irregularities on the saddles which prevent from scanning in a good way. Nevertheless, even taking into account a $20 \%$ to $30 \%$ conservative error while measuring the non-weldable zones covered by the calibrated strips, PAUT is capable of detecting additional improperly welded zones, apart from the calibrated strips, which can be attributed to so-called "cold welds", as a result of the reduced heating time, as expected. Furthermore, the results of the PAUT evaluation and those of the destructive peel tests according to the ISO 13956 standard have been confronted in order to evaluate the degree of correlation between both techniques. The results show that, in certain conditions, the ISO test fails in revealing all the non-weldable zones due to the test conditions on the one hand, and to the very small size of the strips in the "cross" configuration on the other hand. Moreover, the acceptance criteria of the ISO Tear test which is established currently by means of a visual inspection must be interpreted carefully since this method either underestimates or overestimates the thresholds. In conclusion, PAUT reveals to be a powerful and efficient tool for detecting and sizing disorders at the pipe-saddle interface with regard to the ISO Tear test acceptance criteria. But such results remain to be confirmed and to be validated on other saddle designs prior to establishing the ambitious correlation of the dimensions and location of the defects with the residual lifetime regarding a "Remove/No Remove" decision in the field, as was underlined during the workshop of the 2016 Plastic Pipes Conference XVIII. In this area both welds and plain pipes must be focused on.

\section{Acknowledgments}

Florent Angelini (formerly NDT Engineer Cofrend UT Level 3) at Institut de Soudure Industrie, Villepinte, France) is greatly acknowledged for his long term collaboration in the PAUT joint studies and especially for this work. 


\section{References}

[1] Bird, C., Caravaca, D., and Raude, A. 2006. "The Inspection of Cold Welds in Electrofusion Joints." Presented at the Plastics Pipes XIII, Session 7A, Washington DC, USA.

[2] Fabiano, A. 2005. "New Developments in NDE for PE Pipe." Presented at the American Gas Association Conference, Plastic Materials.

[3] Hwang, J. S., Shin, H. J., Song, S. J., and Song T. K. 1999. 26th Review of Progress in Quantitative Non-destructive Evaluation, edited by D.O. Thompson and D.E. Chimenti, 19A (509): 1087-93.

[4] Troughton, M. 2001. "Welding with Integrated Non-Destructive Examination of PE Pipes." Presented at the Plastics Pipes XI, Munich, Germany.

[5] Kitaoka, T., Furukawa, J., Toda H., and Murata, Y. 2001. "Development of Electrofusion Interface Ultrasonic Inspection Technique Contributing to Construction of Highly Reliable PE Piping." Presented at the 2001 International Gas Research Conference, DP-15, Amsterdam, The Netherlands.

[6] Munns, I. J., and Georgiou, G. A. 1999. "Ultrasonic and Radiographic NDT of Butt Fusion Welded Polyethylene Pipes." Insight 41 (5): 291.

[7] Shin, H. J., Kwan, J.-R., and Song, S.-J. 2001. "Ultrasonic Real Time Imaging Technique for the Inspection of Electrofusion Joints for Polyethylene Piping." In 2001 Forum for Gas Safety, edited by Korea Gas Safety Corporation, KGS 2001-069, 21.

[8] Scholten, F. L., and Shin, H. J. 2006. "Non-Destructive Ultrasonic Inspection to Detect Flaws in Plastic Pipe Walls and Joints." Presented at the Plastics Pipes XIII, Session 7A, Washington DC, USA.

[9] Troughton, M. 2012. "Development of an Automated Phased Array Ultrasonic Inspection System and Flaw Acceptance Criteria for Welded Joints in Polyethylene Pipes." Presented at the Plastic Pipes XVI, Barcelona, Spain.

[10] Striplin, T. H. 1998. "Non-Destructive Testing of Electrofused Joints and Large Diameter Gas Pipes." In Proceedings of the Plastics Pipes X, 585-94.

[11] Troughton, M., Jones, I., and Andrews, S. 2013. "State of the Art in Welding Thermoplastics and in Assessing Thermoplastic Welded Joints." Presented at the Giornate Nazionali della Saldatura dei Materiali Plastici e Compositi, GNS7, Genoa, Italy.

[12] Petersen, H., and Striplin T. H. 1995. "Examination of American and Danish Butt Fusion Joints and Test Methods in Thermoplastics Material." In Proceedings of the 14th International Plastic Fuel Gas Pipe Symposium, 153-67.
[13] Striplin, T. H. 1997. "Non-destructive Testing of Electrofused Joints and Large Diameter Gas Pipes Technology to Reduce Costs and Ensure Reliability in Distribution Systems Worldwide." In Proceedings of the 1997 International Plastic Pipe symposium, 325.

[14] Savitski, A., and D'Zurko, D. 2001. "Butt Joint Evaluation Method." In Proceedings of the 2001 International Gas Research Conference, Amsterdam, The Netherlands.

[15] Troughton, M., and Khamsehnezhad, A. 2016. "Development of Flaw Acceptance Criteria for Welded Joints in PE Pipes." Presented at the Plastic Pipes XVIII, Berlin, Germany.

[16] Bergman, M., and Jacobson, K. 2016. "Digital Radiography of PE Joints." Presented at the Plastic Pipes XVIII, Berlin, Germany.

[17] Stakenborghs, R. J. 2016. "Interaction of Microwave Energy with HDPE and Its Uses for Inspecting Thermal Fusion and Base Material." Presented at the Plastic Pipes XVIII, Berlin, Germany.

[18] Stefan, K. S., Hochrein, T., and Heidemeyer, P. 2016. "Potentials of Terahertz Technology for the Inspection of Plastic Pipes." Presented at the Plastic Pipes XVIII, Berlin, Germany.

[19] Gueugnaut, D., Piovano, M., Garneret, G., Sèvre, B., Vacchina, A. M., and Cantore, C. 2008. "Evaluation of a New Non-Destructive Technique of the Polyethylene Welded Assemblies." Presented at the 2008 International Gas Union Research Conference, Distribution Session N¹96/E/S2, Cité des Sciences et de 1'Industrie, Paris, France.

[20] Seonghee, K., and Kee, B. Y. 2012. "Inspection Results of Damaged Polyethylene Electrofusion Joints Using Ultrasonic Imaging Method." Presented at the Plastic Pipes XVI, Barcelona, Spain.

[21] Seonghee, K. 2014. "Non Destructive Evaluation of Improper Fusion for Polyethylene Heat Fusion Socket Joint." Presented at the Plastic Pipes XVII, Chicago, Illinois, USA.

[22] ISO TC138/SC5 ISO/DTR16943. 2014. “Thermoplastic Pipes for the Conveyance of Fluids-Inspection of Polyethylene Electrofusion Socket Joints Using the Phased Array Ultrasonic Testing Method."

[23] Postma, P. J., and Hermkens, R. J. M. 2012. "Suitability of Non Destructive Techniques for Testing Polyethylene Pipe Joints." Presented at the Plastic Pipes XVI, Barcelona, Spain.

[24] Gueugnaut, D., Boujlal, A., Sèvre, B., and Angelini, F. 2012. "The Capability of the Ultrasonic Phased Array Technique for Detecting and Measuring Defects at the Inner Surface of a Polyethylene Pipe through an Outside Analysis.” Presented at the Plastic Pipes XVI, Barcelona, 
Spain.

[25] Gueugnaut, D., Angelini, F., Boujlal, A., Bouaffre, R., Sèvre, B., and Louet, P. 2014. "Ultrasonic Phased Array Inspection of Polyethylene Pipelines \& Fittings Used for Gas Distribution.” Presented at the Plastic Pipes XVII, Session 2B, Chicago, Illinois, USA.

[26] Gueugnaut, D., Bouaffre, R., Lopitaux, A., Renaud, R., Angelini, F., and Louet, P. 2016. "Ultrasonic Phased Array Evaluation of the Integrity of Polyethylene Piping Systems." Presented at the 19th World Conference on Non-Destructive Testing, Munich, Germany.

[27] Gueugnaut, D., Angelini, F., Bouaffre, R., and Tessier, M. 2016. "Ultrasonic Phased Array Inspection of Polyethylene Damaged Pipes with Calibrated Faults." Presented at the Plastic Pipes XVIII, Berlin, Germany.

[28] Gueugnaut, D., Blouet, P., Ouakka, A., and Dang Van, K. 1998. "Criteria for Natural and Mechanical Damage to Polyethylene Gas Pipes. Experimental and Numerical Approach.” Presented at the International Gas Research Conference, San Diego (CA), USA.

[29] Gueugnaut, D., Boujlal, A., Sèvre, B., Lopitaux, A., and Constantinescu, A. 2008. "Evaluation of the Residual Lifetime of PE Piping Systems with Point Load Effects: New Coupled Experimental-Numerical Method to Characterize the Performances of New and Old Pipes Excavated from the Networks." Presented at the International Gas Union Research Conference, No197/E/S2, Cité des Sciences et de l'Industrie, Paris, France.

[30] Gueugnaut, D., Boujlal, A., Lopitaux, A., and Constantinescu, A. 2012. "Analysis Of Slow Crack
Initiation of Old Polyethylene Resins by Means of An Elasto-Visco-Plastic Rheological Model: Experimental and Numerical Approach." Presented at the Plastic Pipes XVI, Session 5A, Barcelona, Spain.

[31] Gueugnaut, D., Boujlal, A., Lopitaux, A., and Bouaffre, R. 2014. "The 'Notched Cylindrical Bars under Constant Load Test' (NCBT) as a Means to Assess the Resistance to Crack Initiation and to Slow Crack Growth of PE100 and PE100 RC." Presented at the Plastic Pipes XVII, Session 10B, Chicago, Illinois, USA.

[32] Gueugnaut, D., Fernandez, C., Bouaffre, R., Sèvre, B., and Angelini, F. 2016. "Research Program for Assessing Seismic Risks on Polyethylene Gas Pipelines.” Presented at the Plastic Pipes XVIII, Berlin, Germany.

[33] ISO 13956. 2010. "Plastics Pipes and Fittings-Decohesion Test of Polyethylene (PE) Saddle Fusion Joints-Evaluation of Ductility of Fusion Joint Interface by Tear Test."

[34] Gueugnaut, D., Garneret, G., Sèvre, B., and Lopitaux, A. 2008. "Evaluation of the Quality of the PE Assemblies Joined by Electrofusion: Analysis of the Standardized Tests Designed to Evaluate the Cohesive Resistance." Presented at the 2008 International Gas Union Research Conference, Distribution Session No199/E/S2, Cité des Sciences et de l'Industrie, Paris, France.

[35] NF EN 1555. 2011. "Plastic Piping Systems for the Supply of Gaseous Fuels-Polyethylene (PE)-Part 3: Fittings."

[36] NF EN 13100-3. 2005. "Non Destructive Testing of Welded Joints in Thermoplastics Semi-finished Products-Part 3: Ultrasonic Testing. 